\title{
O Ontem e o Hoje na Construção do Livro Didático de Português
}

\author{
Andréia da Cunha MALHEIROS SANTANA* \\ Rafaela Cristine MERLI**
}

* Doutora em Educação pela Universidade Estadual de São Paulo- UNESP (2010). Professora Doutora Adjunto II-

UEL. Contato: andreiacunha@uel.br

** Mestre em Educação pela Universidade Estadual de Londrina- UEL (2019). Contato: rafaelamerli@yahoo.com.br

\begin{abstract}
Resumo:
Este artigo analisa algumas mudanças ocorridas nos livros didáticos de português e as relaciona com as próprias alterações no ensino da língua materna. Ele é fruto de uma pesquisa documental realizada a partir da comparação de dois livros publicados em épocas diferentes: 1969 e 2018. A partir dessa comparação, foi possível refletir sobre o percurso socio-histórico do livro didático de português, sua estrutura e concepção teórica. A base teórica deste artigo articula a leitura de diferentes autores que discutem o ensino de língua portuguesa sob diversas perspectivas. Os livros didáticos, por serem um produto cultural, são frutos do contexto sociohistórico e se relacionam com os variados discursos presentes na sociedade, entre eles os documentos oficiais, as teorias linguísticas e de ensino e o próprio público a quem se destina (docente e discente). Como resultado dessa análise, foi possível identificar uma mudança nas concepções teóricas e nas orientações legais que permeiam a disciplina ao longo dos quase cinquenta anos que distanciam as duas obras, tais alterações interferiram na construção dos livros didáticos. Embora haja muitas mudanças (tanto visuais como estruturais), é possível afirmar que os livros didáticos de português ainda apresentam pontos de permanência que o atrelam ao ensino tradicional.
\end{abstract}

Palavras-chave:

Livro didático; português; contexto socio-histórico. 


\section{O Ontem e o Hoje na Construção do Livro Didático de Português}

Andréia da Cunha Malheiros Santana; Rafaela Cristine Merli

\section{A Construção do Livro DidÁtico}

Este artigo tem como objetivo analisar as mudanças ocorridas no livro didático de língua portuguesa por meio dos anos. Para refletir sobre o Livro Didático, doravante LD, é necessário examinar, ainda que parcialmente, o contexto socio-histórico que envolve esse material. Muito além de um simples suporte pedagógico para professores e alunos, o LD traz consigo um emaranhado de conceitos ideológicos, interesses políticos e econômicos, que vão desde a lucratividade por parte do mercado editorial, às concepções de homem, ensino e de sociedade em sua época de produção e recepção.

A necessidade de se transmitir o conhecimento científico historicamente acumulado a muitos estudantes levou a uma produção em massa do LD. Ele é uma forma de transmissão de conhecimento tão intencional quanto o é a sua produção, por isso ao analisá-lo é importante relacioná-lo ao seu contexto histórico.

Outro ponto que merece destaque e influencia a sua construção é o fato de o LD, para participar do PNLD (Programa Nacional do Livro Didático), precisar estar de acordo com o edital de materiais didáticos elaborado pelo MEC (Ministério da Educação), que por sua vez, atende à legislação educacional vigente. Tal exigência não é uma novidade, pois, desde 1938, por meio da lei 1006 (Brasil, 1938), há um controle deste material a fim de garantir que ele atenda aos pressupostos dos programas oficiais. Ao longo do tempo, os documentos legais mudaram e a forma de controle, mas ela sempre existiu.

Atualmente, ter uma edição de livros aprovada no PNLD é interessante para as editoras, pois somente os livros aprovados podem ser adquiridos via FNDE (Fundo Nacional de Desenvolvimento da Educação). Os dados divulgados pelo próprio FNDE mostram como o Estado é um cliente importante: o PNLD adquiriu 172.571.931 exemplares de livros didáticos entre o final de 2019 e início de 2020, totalizando um investimento de R\$1.390.201.035,55, atingindo um público de 32.010.093 estudantes da educação básica.

Silva Ota (2009) também enfatiza o papel do Estado como um bom comprador dos LDs e afirma que, devido ao espaço destinado ao LD na escola, principalmente depois do PNLD, o LD passou a ser a grande vedete do mercado editorial brasileiro, responsável pela grossa fatia de $60 \%$ das vendas de livros no Brasil. Desse percentual de vendas, o Estado era responsável pela compra de 50\% da produção, números ampliados pela inclusão do Ensino Médio no programa, o que justifica a preocupação constante das editoras em oferecer um produto comercialmente cada vez mais interessante, mais competitivo e capaz de se manter no mercado. O livro que fará mais sucesso será aquele que conseguir vender por mais tempo, independente da qualidade.

Tais números justificam as adaptações dos livros aos documentos oficiais e evidenciam, devido à alta distribuição do LD, a sua influência em sala de aula, o que já é reconhecido por diferentes estudiosos tanto da área de currículo como da área de ensino. (Marcuschi, 2005).

\footnotetext{
${ }^{1}$ Informações disponíveis em: https://www.fnde.gov.br/index.php/programas/programas-do-livro/pnld/dados-estatisticos Acesso em 04 mar. 2021
} 
Com o intuito de analisar as mudanças ocorridas no LD ao longo dos anos, foram selecionadas duas obras destinadas para a mesma série, mas em momentos históricos diferentes, a saber: "PortuguêsCurso Ginasial 3", escrito por Horácio Rolim e Jorge Magalhães, publicado pela Editora do Brasil, em 1969 (doravante LD1) e “Tecendo Linguagens”, escrito por Tânia Amaral Oliveira e Lucy Aparecida Melo Araújo, publicado pela Ibep, em 2018, (doravante LD2). Este artigo foi construído com base nas orientações da pesquisa qualitativa, de cunho documental (Gil, 2002) e teve como base teórica a Pedagogia Histórico-Crítica e a concepção sociointeracionista de ensino. Essa escolha teórica permitiu uma análise longitudinal dos objetos escolhidos, os relacionando com a compreensão dos acontecimentos históricos pelo viés social, isto é, a partir da perspectiva de que as relações intrínsecas da natureza humana se dão por meio da produção de bens materiais, sendo o LD um destes bens materiais.

Para melhor evidenciar as diferenças na construção dos dois materiais, mantivemos o foco desta análise longitudinal em três pontos principais:

1. Capa: título e aspectos visuais do livro (tamanho, ilustração, diagramação da página);

2. Apresentação do livro e sumário: indicação dos conhecimentos/competências trabalhadas;

3. Abertura da unidade: aspectos visuais e interação com o aluno

O recorte escolhido para este artigo torna-se relevante à medida em que se faz necessário compreender que o LD foi modificado ao longo do tempo em virtude de públicos diferentes, necessidades e contextos socio-históricos variados, entretanto alguns pontos foram mantidos. Dessa forma, podese entender que o LD é um material que não apenas transmite o conhecimento científico acumulado historicamente, mas que reflete as demandas sociais vigentes em determinado contexto.

\section{O Livro Didático Através do Tempo}

Os LDs surgiram com o objetivo de auxiliar o trabalho do professor com técnicas e métodos de execução pedagógica. Em 1937, portanto durante o Estado Novo², o LD chegou às escolas brasileiras com a criação de um órgão específico para legislar sobre tal fim: o Instituto Nacional do Livro (INL) (Brasil, 1937), que fornecia obras didáticas para alunos das redes públicas. No entanto, o termo "livro didático" apareceu pela primeira vez em 1938, na Lei 1006:

Art. $1^{\circ}$ É livre, no país, a produção ou a importação de livros didáticos. Art. $2^{\circ}$ Para os efeitos da presente lei, são considerados livros didáticos os compêndios e os livros de leitura de classe. (BRASIL, 1938).

Nesse período, o termo "livro didático" foi utilizado para nomear o material adotado especificamente para a escola, destinado ao ensino, obedecendo aos programas curriculares escolares; desde essa época, tal material já se apresentava como algo articulado aos documentos oficiais. Para garantir que o material estivesse de acordo com as orientações oficiais, a lei 1006 (Brasil, 1938) criou a Comissão Nacional do Livro Didático (CNLD), que tinha por objetivo verificar se os livros atendiam aos pressupostos dos programas oficiais, mas, diferentemente do PNLD, não avaliava a qualidade dos livros. Esta comissão estabelecia que: "a partir de $1^{\circ}$ de janeiro de 1940, nenhum LD poderia ser adotado no ensino das escolas pré-primárias, primárias, normais, profissionais, e secundárias no país sem a autorização prévia do Ministério da Educação e Saúde” (FERREIRA, 2008, p. 38)

Cabia à CNLD fazer a seleção dos livros que seriam utilizados pelas escolas. Dessa forma, desde o seu início, os LDs tiveram a tarefa de selecionar os conteúdos curriculares a partir das orientações oficiais.

${ }^{2}$ O Estado Novo durou de 1937 a 1945. Para saber mais: BOMENY, Helena MB. Repensando o estado novo. Rio de Janeiro: FGV, 1999. 
A partir de 1960, sob regência do regime ditatorial, tanto a produção quanto a distribuição dos livros didáticos foram controladas mais intensamente pelo governo. A fim de reforçar esse controle, em 1966, o governo instituiu a Comissão do Livro Técnico e do Livro Didático (COLTED), que teve por responsabilidade a produção, edição, seleção e distribuição de livros técnicos e didáticos. (BRASIL, 1966) A COLTED contratava autores e editoras que seriam responsáveis pelo material, adequando-os às exigências do governo, para então serem distribuídos às escolas. Cabia às editoras e aos autores obedecer a COLTED.

O programa mudou de nome ainda algumas vezes até que em 1985, através do Decreto ${ }^{\circ}$ 91.542, o PNLD surgiu. No momento de abertura política, o LD foi pensado como um material que pudesse, além de transmitir o conhecimento teórico, guiar professor e aluno e proporcionar uma aprendizagem mais eficiente às novas exigências do mundo, sobretudo do mercado de trabalho, uma vez que o acesso à escola pública estava sendo ampliado gradativamente.

Para Silva Ota (2009), a popularização do LD ocorreu devido à expansão da educação e da má formação docente3. O professor deixou de ser um membro da elite e passou a receber um alunado que, muitas vezes, tinha pouco acesso à cultura escrita. Dentro dessa nova realidade, o LD surgiu para suprir uma carência tanto dos docentes como dos discentes. Para a autora, o controle curricular exercido pelo LD se torna mais denso à medida que a formação do professor se faz mais precária e sua jornada de trabalho mais exaustiva. É nesse contexto que o LD se insere de forma decisiva no cotidiano escolar, vindo suprir as deficiências da formação docente ao trazer roteiros preestabelecidos, conteúdos já selecionados e mesmo respostas prontas, automatizando, concomitantemente, o mestre e o aluno, reduzidos a máquinas de repetição material.

Geraldi (1997) enfatiza o perigo da má formação docente e afirma que, muitas vezes, não é o professor que adota o LD, ao contrário, ele é adotado pelo LD, pois se torna dependente dele, devido a uma série de fatores, tais como: as facilidades que o LD proporciona, a escassez de materiais didáticos e a falta de uma política de formação adequada. Dionísio (2001) complementa a fala de Geraldi e considera fundamental os cursos de formação de professores formarem seus alunos para que possam, enquanto futuros professores, elaborarem seu próprio material didático para que o LD não seja um objeto formador de professores em si mesmo, já que, conforme Silva Ota (2009, p. 249), o LD é, muitas vezes, “a única fonte frequente de leitura de professores e professoras."

Dionísio (2001) afirma ainda que os professores deveriam saber o porquê dos conteúdos selecionados e as implicações das estratégias utilizadas nos livros didáticos. Os autores de LDs costumam apresentar um "manual do professor", em que esclarecem sobre as correntes teóricas em que fundam suas obras, mas nem sempre há uma correlação entre tais teorias e as atividades propostas no livro do aluno. Muitas vezes, os autores dizem ser adeptos de uma determinada concepção de ensino, mas não conseguem colocá-la em prática e acabam repetindo métodos de ensino ultrapassados que não correspondem aos avanços da área. Dionísio ainda destaca que a boa formação docente é essencial, pois o professor malformado tem dificuldade para perceber a manipulação presente no LD e lidar com ela de forma correta.

Para Bittencourt (1993, p. 6), a situação é preocupante, pois “o espaço escolar está associado intrinsecamente à construção do LD considerando que a escola é, fundamentalmente, uma instituição contraditória onde dominação e conflitos convivem no quotidiano de alunos e professores.” O professor precisa saber usar o LD e reconhecer que ele não é neutro, ele pode auxiliar o trabalho do docente, mas não o substituir.

A educação e, consequentemente, o ensino de língua portuguesa devem ser concebidos como uma prática de transformação social, um processo de ensino-aprendizagem no qual os conteúdos devem

\footnotetext{
${ }^{3}$ Vale destacar que este artigo não pretende discorrer sobre a qualidade da formação de professores e o que levou a uma "má formação docente", mas entende que esta formação deficitária é parte de um processo de desvalorização, mercantilização e sucateamento da educação.
} 
ser trabalhados, refletidos e reelaborados pelo professor e, posteriormente, pelo educando para que esse possa ser um sujeito social e se apropriar das aquisições históricas da sociedade. O LD tem um papel fundamental nesse processo, pois ele é amplamente utilizado nas redes públicas ${ }^{4}$ de ensino, por isso é preciso reconhecer o que ele nos diz de maneira implícita.

\section{O Que Cada LD Nos Diz}

Para analisarmos os livros didáticos selecionados, precisamos compreender o contexto sociohistórico em que cada um foi produzido. O LD1 foi utilizado num momento histórico ditatorial no Brasil. Nesse contexto, ele era controlado explicitamente pelo Estado, que avaliava seu conteúdo para que então pudesse ser distribuído. Os LDs produzidos nesse momento evidenciavam as técnicas de ensino daquela época, com instruções programadas e estudos dirigidos (FILGUEIRAS, 2015).

Já o LD 2 foi produzido num momento em que a concepção de língua adotada pelo PNLD era interacionista. De acordo com esta concepção, a língua deve estar vinculada aos contextos e condições de produção, devendo levar em consideração os diferentes sentidos por ela assumidos em diversas situações sociocomunicativas. Mesmo atrelado a outro momento histórico, o LD2 também está sujeito aos documentos oficiais e ao consequente controle estatal, uma vez que atende ao edital de materiais didáticos elaborado pelo MEC.

O primeiro contato que temos com qualquer livro é a sua capa. Ela é a primeira parte a ser vista e muitas vezes tem sido ignorada, embora nos forneça informações importante sobre a obra e o seu contexto histórico.

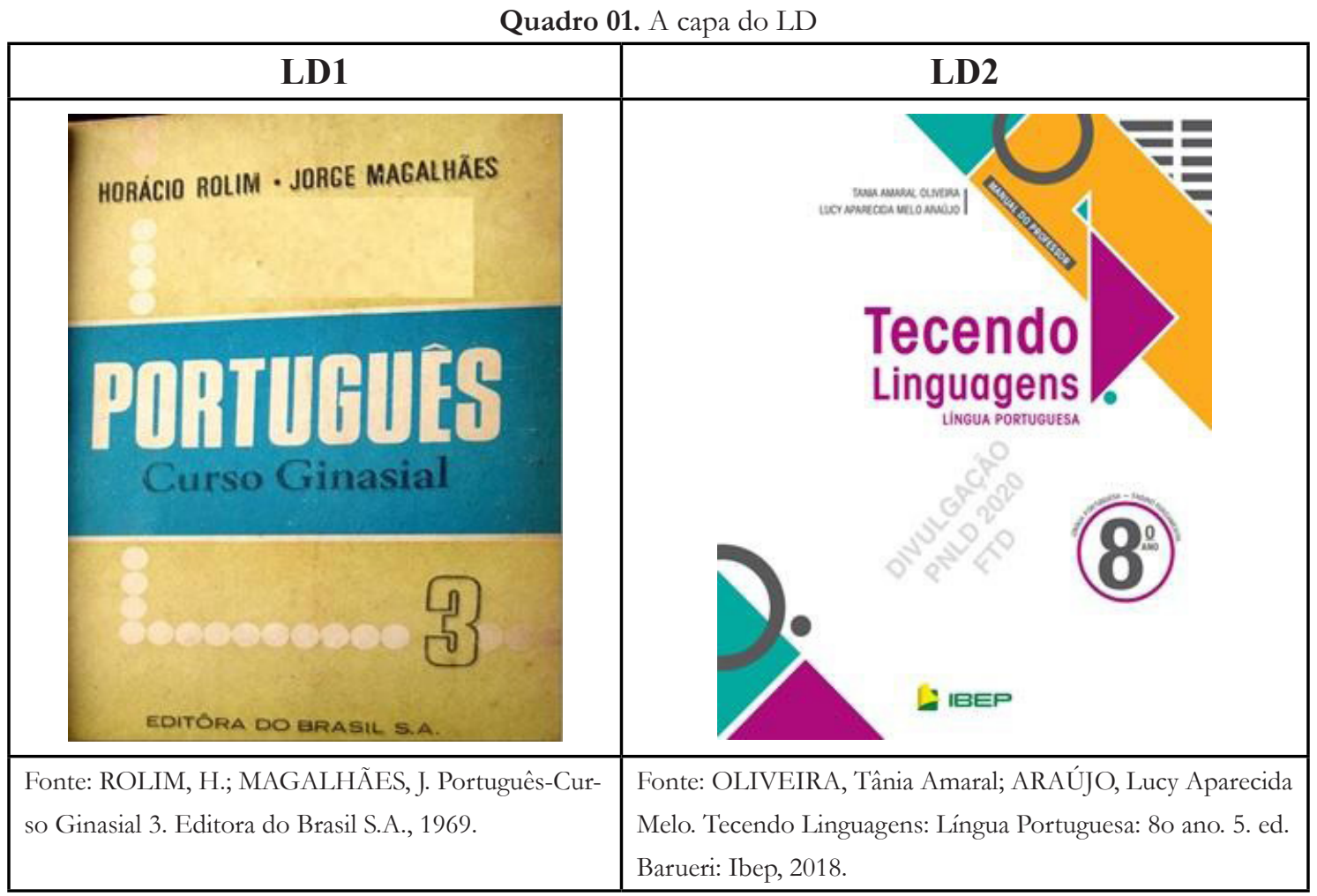

${ }^{4}$ As redes de ensino particular, normalmente, adotam o sistema apostilado, mas há algumas que optam pelo LD. 
O LD1 tinha 20X15cm de tamanho, aproximadamente 180 páginas ${ }^{5}$, a sua capa apresentava duas cores (azul e bege), sem ilustrações, não havia "manual do professor" e as atividades não continham respostas. Não é possível saber se a cor azul presente na capa se alterava de acordo com a série à qual o livro se destinava. O LD2 apresenta uma estrutura bastante diferente, fruto de um distanciamento temporal de quase 50 anos. Por isso é necessário o que Soares (2002) chama de um "olhar socio-histórico" para os dois materiais, pois as alterações na capa, na diagramação, na organização do LD são aspectos influenciados pela época de produção do material. Essa alteração na estruturação do material ocorreu por diversos fatores já descritos neste artigo, como a própria mudança no edital que regulamenta a compra de livros didáticos $^{6}$, a alteração no perfil de professores e alunos, aliados à integração dos estudos da área da linguística ao ambiente escolar e às críticas que o LD recebeu durante a década de 1990, bem como o desenvolvimento de novos recursos gráficos que muitas vezes proporcionaram o que Lins (1977) chamou de Disneylândia pedagógica.

O LD2 tem 28x19cm de comprimento, 288 páginas, a sua capa apresenta um layout com 4 cores, com destaque especial para o título escrito em magenta, num fundo branco. A cor do título muda de acordo com a série à qual se destina. O LD2 tem um "manual docente" com dicas de leitura, sugestão de complementação de atividades, um detalhamento da concepção teórica que guiou a sua organização e uma explicação sobre a forma como atende às orientações dos documentos oficiais, principalmente a BNCC (Base Nacional Comum Curricular). Além disso, o livro do docente apresenta respostas para todas as questões, vale destacar que este livro segue as orientações do edital do PNLD/2020.

O exemplar do estudante não contém o "manual docente", nem espaços para que o estudante possa inserir suas respostas (o livro não é consumível) e deve ser aproveitado para 3 anos.

$\mathrm{Na}$ capa de ambos os livros, encontramos o título e este já denuncia as diferentes concepções de língua e de ensino dos dois momentos socio-históricos. Entre 1969 e 2018, houve uma mudança na maneira de compreender a própria língua. O LD1 tem como título "Português- Curso Ginasial", já o LD2, “Tecendo Linguagens". Essa alteração no campo lexical evidencia a própria mudança no eixo de ensino, pois o LD1 escolheu o título que nomeava a disciplina naquela época, indicando, inclusive, o nível ao qual se destinava. Por sua vez, o LD2 adota a forma nominal do verbo “tecer", utilizada no gerúndio. Tal forma verbal indica que algo ainda está acontecendo, demonstrando uma continuidade e uma certa duração desta ação, o que se associa facilmente à ideia de interação, que se articula ao propósito do livro que se propõe a trabalhar a linguagem em diferentes situações reais de comunicação e vivência. Neste sentido, Patriota (2015) fala de uma "virada pragmática" no ensino de língua e gramática na década de 1990, que resultou numa diversificação dos objetos de ensino, integrando ao cotidiano escolar temas como a oralidade, a variação linguística e a multiplicidade de gêneros.

Outro ponto que merece destaque é o diálogo estabelecido com o docente e o discente. O LD1 apresentava capa, contracapa, uma página com informações similares à da capa, sumário e as "lições". O LD2 traz uma apresentação para o docente, somente presente no exemplar do professor, e uma apresentação discente, presente nas duas versões, conforme imagem abaixo:

\footnotetext{
${ }^{5}$ Esta informação pode não ser exata, pois o livro apresenta muitos sinais de uso.

${ }^{6}$ Para mais informações sobre estas alterações, ver : CAMPOS, M. T. R. A. et al. Edital de compra de livro didático de língua portuguesa para o Ensino Médio: uma arena discursiva de muitas vožes. 2014. Disponível em: https://sapientia.pucsp.br/handle/ handle/13687 Acesso 17 jun.2021
} 
Quadro 2. Apresentação LD2

\begin{tabular}{|c|c|}
\hline Apresentação Docente & Apresentação Discente \\
\hline APASENaCA0 & APRESENTACTOO \\
\hline $\begin{array}{l}\text { Fonte: OLIVEIRA, Tânia Amaral; ARAÚJO, Lucy } \\
\text { Aparecida Melo. Tecendo Linguagens: Língua Portuguesa: } \\
\text { 8o ano. 5. ed. Barueri: Ibep, } 2018 .\end{array}$ & $\begin{array}{l}\text { Fonte: OLIVEIRA, Tânia Amaral; ARAÚJO, Lucy } \\
\text { Aparecida Melo. Tecendo Linguagens: Língua Portuguesa: } \\
\text { 8o ano. 5. ed. Barueri: Ibep, } 2018 .\end{array}$ \\
\hline
\end{tabular}

A apresentação destinada ao professor traz informações importantes com o objetivo de auxiliálo a compreender melhor o LD, funcionando como uma introdução ao "manual do professor". Nesse sentido, é possível perceber que esse texto é um importante contato do professor com o LD, informandolhe que o tal livro tem a "finalidade de oferecer subsídios para seu trabalho em sala de aula e ajudálo a aprimorar conhecimentos teóricos e metodológicos sobre conceitos importantes que embasam as propostas de ensino-aprendizagem apresentadas nesta coleção.” (OLIVEIRA; ARAÚJO, 2018, p. III).

A partir desse excerto, compreendemos que o LD, além de trazer os conteúdos e atividades propostos aos alunos, traz, também, um embasamento teórico para o professor, isto é, o LD atua como um formador do professor. Isso também pode ser percebido no trecho da apresentação:

(...) esperamos que possa desfrutar do material e que ele colabore, de forma efetiva, com a prática e com o processo de ensino-aprendizagem, conduzidos por você e nos quais desempenha papel fundamental, ao lado de cada um dos que firmam o contrato mútuo de aprender e educar. (OLIVEIRA; ARAÚJO, 2018, p. III)

Dessa forma, observamos que os autores objetivam estabelecer uma motivação para que o professor utilize o material de forma efetiva, ou seja, para que ele leia as orientações a ele destinadas e as utilize em seu favor e de seus alunos.

Acreditamos que o LD deve ser um recurso para o trabalho do professor e não seu "mestre", sendo mais um objeto que contribua com a prática pedagógica, mas que não a determine. Entretanto, sabemos que, em muitos casos, o LD é o único material a que o professor tem acesso, fazendo com que esse o utilize como sua única fonte de leitura e pesquisa, regulando todo o processo da prática docente.

Outro ponto relevante da apresentação destinada ao docente é o fato dela explicitar que toda a proposta pedagógica do LD é baseada nos pressupostos da BNCC, a partir das competências, habilidades e eixos nela estabelecidos para a área de Linguagens. Isso é muito importante, pois demonstra que o LD está atualizado em relação aos documentos oficiais, estando alinhado às ideias desse documento que é a diretriz oficial do Brasil em relação aos conteúdos e métodos pedagógicos. 
A BNCC considera que o estudante está cada vez mais interagindo com diversos tipos de interlocutores, principalmente por meio do uso das redes sociais. Assim, o documento propõe que, além dos gêneros que circulam na esfera pública, também é necessário levar em consideração práticas de linguagem contemporâneas, como o curtir, comentar, redistribuir, publicar posts etc. (BRASIL, 2017). É possível afirmar que a concepção de língua da BNCC é sociointeracionista, ou seja, a língua deve ser trabalhada dentro de contextos reais de uso, e não como regras gramaticais isoladas.

Por fim, em relação à apresentação do LD para o professor, enfatizamos que os autores procuram estabelecer uma relação dialógica com o professor, conforme dito anteriormente, o que se comprova a partir do trecho: "Consideramos que cada volume da coleção constitui uma obra aberta e flexível, em contínua construção; um convite à reflexão e à recriação; um ponto de partida para o estabelecimento de um rico diálogo entre autores, professor e alunos." (OLIVEIRA; ARAÚJO, 2018, p. III). Essa relação permite que o professor se coloque como detentor do saber, capaz de refletir sobre o LD e o seu uso nas práticas didáticas. Para Saviani (2013), as práticas pedagógicas devem estimular a atividade e a iniciativa dos alunos, sem desconsiderar as iniciativas do professor, o professor é o mediador do conhecimento historicamente acumulado pelos homens, proporcionando ao aluno uma nova forma de enxergar o mundo, para então poder modificá-lo. Essa ideia pode ser percebida nesse trecho retirado da apresentação ao professor.

Da mesma forma que a apresentação destinada aos professores, a apresentação para discentes também procura estabelecer um diálogo com esse público, introduzindo, além do conteúdo a ser abordado ao longo do LD, os objetivos da obra em relação aos estudantes:

O nosso propósito é despertar em vocês, ou mesmo reforçar àqueles que já estão despertos, o desejo de apropriação da língua portuguesa como o instrumento que intermedeia o seu contato com várias esferas de suas relações: a família, a escola, o bairro, a cidade, o país... o mundo! (OLIVEIRA; ARAÚJO, 2018, p. 3).

Esse trecho também nos mostra que o LD pretende colocar o aluno como sujeito da sua própria aprendizagem, isto é, colocá-lo no centro do processo de ensino-aprendizagem, tornando-o protagonista de sua história.

Além disso, a apresentação também traz orientações ao estudante: "Pesquisem, expressem suas ideias, sentimentos, sensações; registrem suas vivências, construam e reconstruam suas histórias; (...) lutem por seus ideais e aprendam a defender suas opiniões, oralmente e por escrito.” (OLIVEIRA; ARAÚJO, 2018, p. 3) Essas diretrizes confirmam o propósito do LD de tratar o aluno como sujeito de sua própria formação.

Também é importante ressaltar que o LD2 traz essas duas apresentações com o intuito de introduzir a obra tanto para o professor quanto para os alunos, estabelecendo uma relação dialógica com ambos, o que não acontece no LD1. Ter esta preocupação em colocar o professor e o aluno como sujeitos ativos no processo de ensino é uma característica que diferencia os dois livros.

Outro ponto que destacamos neste artigo foi o sumário, ambas as edições apresentam um sumário, mas com características diferentes: 


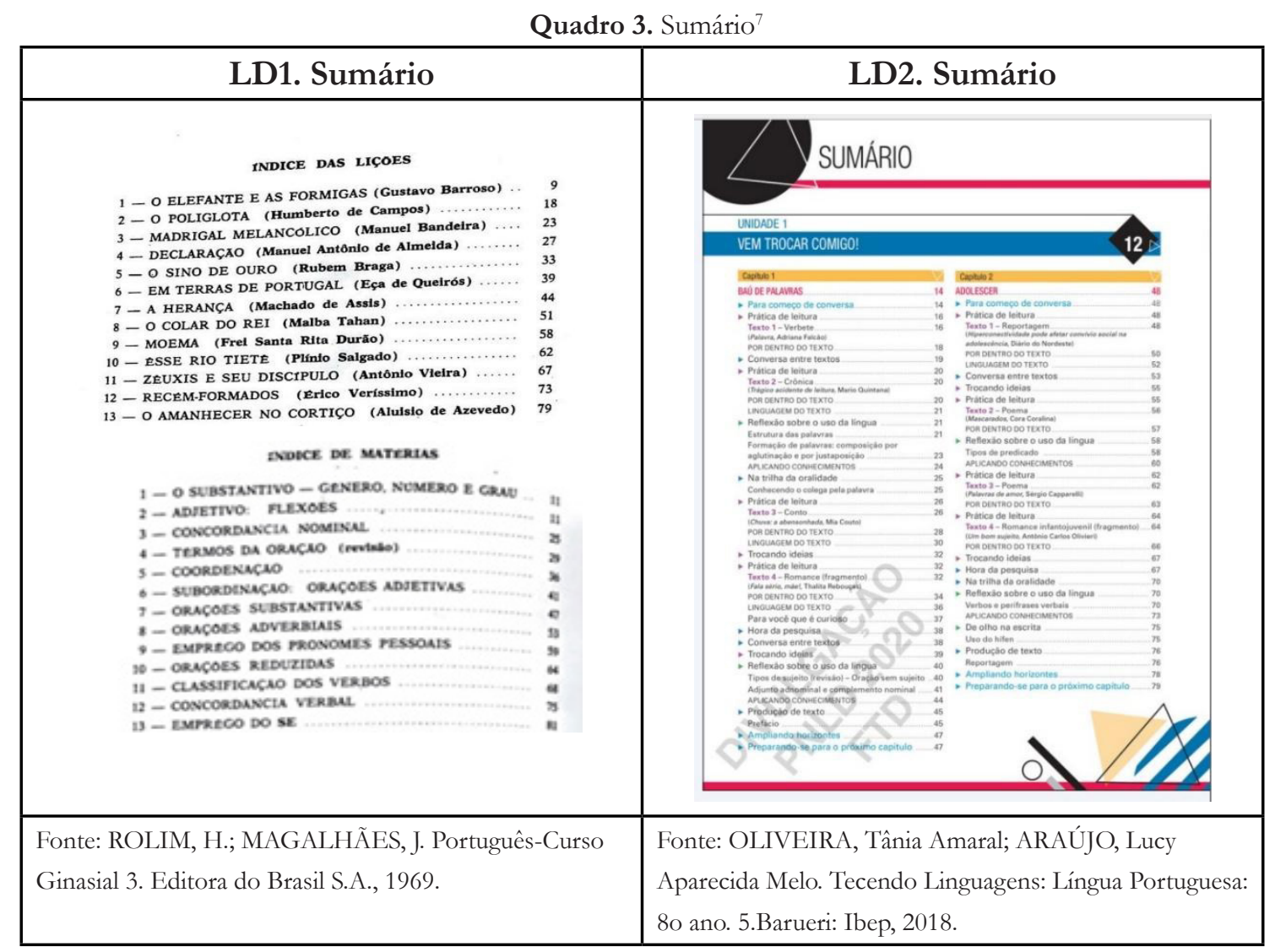

Os sumários apresentados evidenciam mudanças tanto na sua estrutura, quanto no seu conteúdo. No LD1, o sumário ocupava 2 páginas e era dividido em "lições", uma destinada à interpretação de textos e a outra destinada à gramática, cada lição destinada à interpretação apresentava um único texto, não havia atividades destinadas à produção textual, nem tampouco à oralidade.

A diversidade de gêneros, como evidenciam as imagens do LD1 no quadro 3, era bastante limitada e se mantinha no que Bakhtin (2003) chama de gêneros secundários, oriundos da literatura. Desta forma, caberia ao estudante do 8o. ano a leitura e compreensão de crônicas, poemas, trechos de romances advindos tanto da literatura nacional como internacional.

Conforme apontam os estudos de Patriota (2015), o LD1 é fruto de uma época de transição na produção de material didático. As produções da década de 1970 estavam se afastando gradativamente daquelas utilizadas durante as primeiras décadas do século XX, que eram caracterizadas, em sua maioria, por antologias literárias, livros de retórica e livros de gramática; o ensino de português, naquela época, acontecia nestas três frentes independentes. Para Bunzen (2011), esta transição ainda se acentuará nas décadas seguintes com críticas oriundas do meio acadêmico que apontavam falhas tanto na articulação dos LDs aos documentos oficiais quanto aos estudos linguísticos da época.

No LD1, é possível perceber que a interpretação e a gramática dividem o mesmo livro, embora ainda não estejam articuladas. Essa falta de articulação entre o eixo leitura e o eixo análise linguística está relacionada à concepção de língua vigente no momento de produção de LD1, por isso é necessário considerarmos esses aspectos ao analisarmos um LD de diferentes épocas, pois o contexto socio-histórico e a visão de língua influenciam diretamente na produção desse material, o LD reflete o seu tempo e o ensino de português daquele momento.

\footnotetext{
${ }^{7}$ O "sumário" do LD2 apresenta 4 páginas, para que a imagem não ficasse excessivamente reduzida, optamos por inserir apenas 1.
} 
No início do século XX, a concepção de língua vigente não entendia o estudante enquanto sujeito, o estudante deveria ser estimulado pela repetição para que pudesse realizar alguma atividade. Nessa perspectiva empirista, conforme afirma Becker (2001), o sujeito nasce como uma folha em branco, sendo que o ambiente lhe proporcionará o conhecimento; nessa concepção, o sujeito é passivo na aprendizagem, recebendo as informações que lhe são transmitidas, aprendendo pelo hábito e pelos estímulos externos, por isso o livro não interage com o estudante.

O que se pode observar, então, é uma concepção de língua normativa, na qual, as circunstâncias do ato comunicativo não são consideradas no estudo da língua. Conforme Koch (2006, p. 14), essa concepção de língua corresponde a um sujeito determinado, "assujeitado pelo sistema, caracterizado por uma espécie de "não consciência", não permitindo que o aluno, neste caso, seja dono de sua verdade: "sua consciência, quando existe, é produzida de fora e ele pode não saber o que faz e o que diz." Para a autora,

Quem fala, na verdade, é um sujeito anônimo, social, em relação ao qual o indivíduo que, em dado momento, ocupa o papel de locutor é dependente, repetidor. Ele tem apenas a ilusão de ser a origem de seu enunciado, ilusão necessária, de que a ideologia lança mão para fazê-lo pensar que é livre para fazer e dizer o que deseja. Mas, na verdade, ele só diz e faz o que se exige que faça e diga na posição em que se encontra. (KOCH, 2006, p. 14).

Assim, o livro parece reproduzir uma abordagem única, objetiva e regulada, como era comum na época em que foi produzido. Nesse sentido, a afirmação anterior de Koch confirma a ideia de que o LD1 propõe que o aluno seja um sujeito passivo, e não um sujeito ativo no processo de interpretação de texto. Pelo viés ideológico, podemos perceber que o livro ensina técnicas que poderão ser utilizadas diretamente em situações de reprodução das condições de produção, ou seja, aprender a interpretar e a escrever textos tidos como "clássicos" servirá para que o aluno não somente aprenda essas técnicas, mas que ele as reproduza futuramente, considerando esse modo de ensinar e aprender como o correto, o único e o essencial para se ter trabalhadores que possam, minimamente, exercer sua função e também reproduzir essas condições de produção.

Vale destacar também que, no LD1 não há expresso, explicitamente, momentos de diálogo com os estudantes, isto é, aparentemente não se leva em consideração o conhecimento de mundo que o aluno traz com ele para a escola.

A concepção de língua e de ensino presente no LD1 foi majoritária durante bastante tempo, até que na década de 1980, a influência de autores como Bakhtin promoveu uma mudança na compreensão do processo de ensino que passa a entender a linguagem como social e essencialmente dialógica, surge a noção de que o sujeito é ativo no processo de aprendizagem; é através da interação entre o sujeito e o objeto de estudo que a aprendizagem, de fato, acontecerá. Os estudos bakhtinianos foram incorporados a muitos documentos oficiais, que regem os editais do PNLD, consequentemente, influenciaram a produção dos LDs.

Diferentemente do LD1, o LD2 apresenta 4 páginas de sumário, ele é organizado em 4 unidades temáticas, a saber "Vem Trocar Comigo", "Com a Palavra, Narradores e Poetas", "Educação é o Caminho" e "Comunicação e Consumo", os temas são diferentes para cada série da coleção. As unidades se subdividem em 2 capítulos, cada capítulo também apresenta um subtema que se relaciona à temática da unidade. Os capítulos se dividem em 3 tópicos: "Para começo de conversa" (com, aproximadamente, 30 páginas), "Ampliando Horizontes" (com, aproximadamente, 01 página), e "Preparação para o próximo capítulo" (com aproximadamente, 01 página). O primeiro tópico, mais denso do que os demais, se subdivide em: "Práticas de leitura", "Na trilha da oralidade", "Hora da Pesquisa", "Reflexão sobre o uso da língua" destinada a algum tema da análise linguística, "Conversa entre Textos" e "Produção de Texto".

Há uma ideia de integração entre o estudo do texto, os estudos de análise linguística e de produção textual. Desta forma, é possível afirmar que o LD2 se adaptou à concepção de ensino atual, bem 
como aos documentos oficiais (como a BNCC (2017)) que apregoam a necessidade de que o estudante tenha contato com os diferentes gêneros textuais que o rodeiam e que a gramática seja trabalhada numa perspectiva que leve em conta o uso da língua.

Entretanto, há algumas permanências nos dois livros que indicam também continuidades no ensino de português. No próprio "Sumário" é apresentada a terminologia específica da área como "Formação de palavras por aglutinação e por justaposição", "Adjunto adnominal e Complemento Nominal”, entre outras. Mesmo sendo um produto novo, reelaborado de acordo com um contexto socio-histórico diferente do LD1, os dois LDs mantêm alguns pontos de semelhança, pois muitos tópicos da gramática normativa estão presentes nas duas edições, embora aproximadamente 50 anos as separem. São eles:

Quadro 4. Conteúdos gramaticais em comum entre os LD

\begin{tabular}{|l|l|}
\hline \multicolumn{1}{|c|}{ LD1 - Conteúdos gramaticais } & \multicolumn{1}{c|}{ LD2 - Conteúdos gramaticais } \\
\hline - Formação palavras: composição e & - Formação de palavras: composição por \\
derivação: os prefixos latinos & aglutinação e justaposição \\
- Termos da oração & - Termos essenciais, integrantes e acessórios \\
da oração & - Concordância nominal \\
- Concordância nominal & - Período composto: coordenação e \\
- Coordenação/ Subordinação: orações & subordinação \\
adjetivas/ orações substantivas / orações & \\
adverbiais/ orações reduzidas & - Parônimos \\
- Homônimos e Parônimos & - Concordância verbal \\
- Concordância verbal & - Regência verbal \\
- Sintaxe de regência & - Verbos e perífrases verbais \\
- Classificação os verbos/ Emprego dos & \\
tempos e modos / Emprego do infinitivo & \\
\hline Fonte: ROLIM, H.; MAGALHÃES, J. Português-Curso & Fonte: OLIVEIRA, Tânia Amaral; ARAÚjO, Lucy \\
Ginasial 3. Editora do Brasil S.A., 1969. & Aparecida Melo. Tecendo Linguagens: Língua Portuguesa: \\
& 8o ano. 5. ed. Barueri: Ibep, 2018. \\
\hline
\end{tabular}

Podemos perceber, portanto, que mesmo com um grande intervalo temporal entre as duas obras, ambas trazem os mesmos conteúdos gramaticais destinados ao oitavo ano. O LD2 traz os conteúdos gramaticais dentro de um tópico, chamado "Reflexão sobre o uso da língua", o que, pelo próprio título, leva-nos à compreensão de que a obra segue, ou ao menos se propõe a seguir, uma visão sociointeracionista da Língua, tentando promover não apenas o ensino pelo ensino, mas o ensino reflexivo baseado no uso da Língua, o que está em acordo com a BNCC. Já o LD1 não expressa a preocupação em articular o ensino da gramática ao uso da Língua, ele apresenta as atividades sem base reflexiva, por meio do conteúdo expositivo e de exercícios de repetição, com o fim de "memorizar" as regras, em vez de compreendê-las em situações reais de uso da Língua.

Bunzen, já apontava em 1999 a permanência dos conteúdos gramaticais; para o autor, "as aulas de língua materna ainda estão moldadas pelo ensino tradicional" (2000, p.01). Mais de 20 anos após esta constatação ainda encontramos um LD preocupado com a nomenclatura gramatical. Corroborando com esta discussão, Dionísio (2001) chama a atenção para esta contradição, muitas vezes, os autores de LDs afirmam seguir determinada concepção teórica, mas nem sempre conseguem fazê-lo. Talvez, ainda estejamos numa fase de transição, repleta de idas e vindas, marcadas muitas vezes por pressões contraditórias: ora temos a adoção de uma concepção interacionista do ensino da língua materna, apoiadas nos estudos de Bakhtin, ora temos uma tendência conservadora/tradicional do ensino, a própria BNCC apresenta esta dualidade. 
A abertura da unidade também traz muitas informações sobre o trabalho realizado com o texto. No LD2, todas as unidades se iniciam com um texto. No LD1, há capítulos que visam a interpretação textual e outros que visam o trabalho com a gramática.

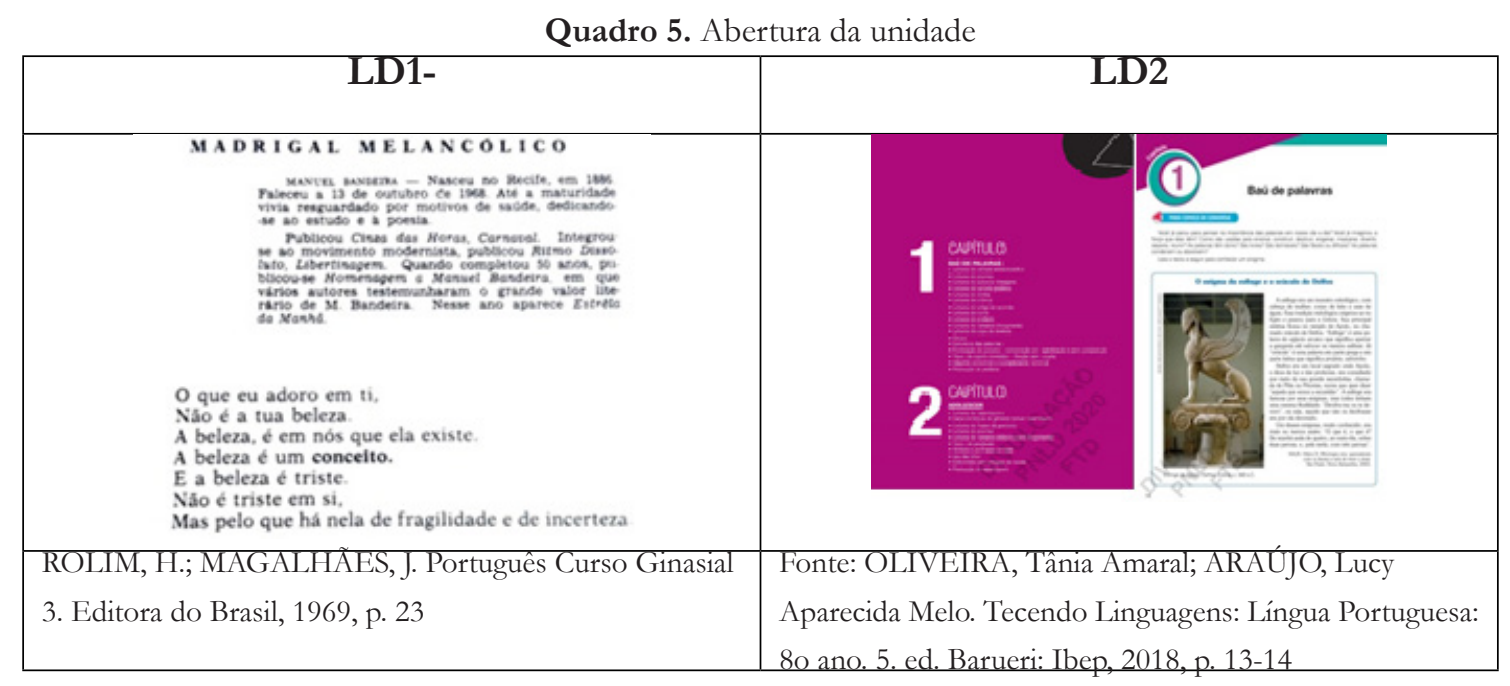

A estrutura dos dois livros sofreu diversas alterações durante os anos. No LD 1, o que se pode perceber é uma página sem cores, sem imagens, sem qualquer tipo de recurso gráfico ou textual que proponha uma interação com o aluno. A unidade se inicia com o título do poema, que aparece em destaque, "Madrigal Melancólico", de Manuel Bandeira, em seguida apresenta-se uma breve biografia e bibliografia do autor. O texto é um poema tido como "clássico". Tais textos eram considerados "ideais" para o ensino de Língua Portuguesa naquele momento. Além disso, não observamos qualquer tipo de interação com o leitor, o que difere do formato atual. Koch e Elias (2013) defendem uma concepção de leitura na qual haja uma interação entre autor, texto e leitor. As autoras acreditam que

Se, por um lado, nesse processo, necessário se faz considerar a materialidade linguística do texto, elemento sobre o qual e a partir do qual se constitui a interação, por outro lado, é preciso também levar em conta os conhecimentos do leitor, condição fundamental para o estabelecimento da interação, com maior ou menor intensidade, durabilidade, qualidade. (KOCH; ELIAS; 2013, p. 19).

Pode-se entender, dessa forma, que o leitor não chega ao texto sozinho. Há uma relação de troca: o leitor deve trazer consigo seu conhecimento de mundo, suas competências já acumuladas, para então realizar a interpretação. Ler o texto somente para analisar asserções linguísticas não permitem essa interação. Nesse sentido, o professor é o mediador entre o aluno e o conhecimento, utilizando-se, para tal fim, do LD. O LD1 pressupõe um sujeito menos ativo em seu próprio aprendizado,

O primeiro ponto a ser destacado é a própria seleção do gênero a ser trabalhado, no LD1 optouse por textos da esfera literária, no LD2, é possível perceber uma variedade de gêneros, como podemos observar no sumário do livro. A leitura e a interpretação de textos são fundamentais para a atuação do sujeito enquanto cidadão, pois são habilidades exigidas não somente no cotidiano, por isso cada unidade explora um número maior de textos de diferentes gêneros textuais.

Há uma mudança no cenário socio-histórico do LD1 (1969) e o contexto do LD2 (2018). Partindo desse ponto de vista, o LD2, diferentemente do LD1, apresenta cores e imagens, fruto do avanço tecnológico que permitiu uma impressão mais atraente ao aluno, além de uma estrutura composicional dos conteúdos na página que visa facilitar o entendimento e a assimilação por parte de quem o lê. 
Além disso, podemos perceber que o LD2 traz uma abertura da unidade com elementos de interação com o leitor/aluno, como o item "Para começo de conversa", acompanhado de uma introdução ao tema que dialoga diretamente com o aluno: "Você já parou para pensar na importância das palavras em nosso dia a dia? Você já imaginou a força que elas têm?(...)" (OLIVEIRA; ARAÚJO, 2018, p.14) Sendo assim, o LD2 apresenta uma concepção de língua interacionista, em que o sujeito se constitui a partir da interação com o outro. Koch (2006) postula que, nessa concepção de língua, o sujeito é visto:

Como entidade psicossocial, sublinhando-se o caráter ativo dos sujeitos na produção mesma do social e da interação e defendendo a posição de que os sujeitos (re)produzem o social na medida em que participam ativamente da definição da situação na qual se acham engajados, e que são atores na atualização das imagens e das representações sem as quais a comunicação não poderia existir. (KOCH, 2006, p. 15).

Dessa forma, colocar o aluno como sujeito de seu próprio discurso, engajá-lo em situações reais de uso dos mais variados gêneros permite que o estudante pense e repense seu lugar enquanto cidadão na sociedade, compreendendo que tem um papel, uma função social. Tal interação supõe que o aluno é um sujeito ativo no processo de aprendizagem, fazendo parte daquilo que lhe é ofertado enquanto conteúdo escolar. Somente depois desta interação com o estudante, o LD2 inicia a Unidade 1, apresentando o texto que será trabalhado durante o capítulo.

\section{Considerações Finais}

A partir deste estudo, foi possível constatar que houve uma expansão na disseminação e importância do LD em sala de aula, sobretudo após a criação do PNLD, o que torna estudos como esse necessários, pois o LD é bastante presente na realidade brasileira e muitas vezes determina o quê e como o ensino será realizado.

A comparação dos dois LDs selecionados mostrou que ele sofreu alterações ao longo do tempo, tais mudanças ocorreram em virtude de avanços tecnológicos, de públicos diferentes, necessidades e contextos socio-históricos diversos, mas também em razão de novos conhecimentos/pesquisas na área de ensino e de linguagem.

O LD2 apresenta uma maior diversidade de gênero textual, uma preocupação em interagir com os estudantes e atrelar o conhecimento curricular com a realidade social deles. Assim, a temática proposta em cada unidade é escolhida pensando no aluno e nas situações comuns a essa faixa etária. Quanto à interação com o professor, o LD atual, embora defenda o papel do professor como um agente ativo do processo educacional, apresenta um material bastante detalhado e pormenorizado que pode guiar todas as ações do docente, o que dependendo da sua formação, carga horária de trabalho e outros fatores, pode levá-lo a ser um simples executor de um "manual”, condicionado à política educacional presente.

As concepções de ensino de língua portuguesa mudaram. Ao interpretar um texto, esperase que o estudante não apenas decodifique a mensagem que lhe é apresentada, mas também construa diversos sentidos para ela, a partir da interação entre sujeito, contexto e texto, pois a interpretação textual necessita dessa relação dialógica para que seja efetiva. O ensino da gramática também sofreu alterações e tem como base a reflexão sobre o uso da língua e seus diferentes contextos. Tais mudanças impactaram a construção dos LDs.

Entretanto, é preciso destacar que o LD2 apresenta como ponto de permanência os mesmos tópicos oriundos da gramática normativa presentes no LD1, embora os LDs tentem inserir as atividades numa lógica dialógica que pretende articular os conhecimentos de mundo dos estudantes, nem sempre 
conseguem fazê-lo, há ainda uma ênfase na terminologia específica e nos conceitos gramaticais. É possível inferir o quão complexa é esta relação e o quanto é difícil romper com esta tradição do "ensino gramatical". Mesmo com o surgimento de novas concepções teóricas, o LD ainda reitera práticas consideradas tradicionais.

Outro ponto de permanência no LD é o controle deste material por parte do Estado, tal controle esteve presente em diferentes momentos históricos, mesmo com nomes diversificados (INL, CNLD, COLTED, PNLD) e atuação mais ou menos explícita, ele se fez presente. Tal controle sobre o que é trabalhado em sala de aula não é feito unicamente pelo LD, há também as avaliações externas.

Para finalizar, é preciso compreender que o LD de língua portuguesa é uma construção sociohistórica, carregada de rupturas e permanências e que esta dualidade ainda está presente tanto nos LDs como no ensino de língua portuguesa.

\section{REFERÊNCIAS}

BAKHTIN, Mikhail. Os gêneros do discurso. In: BAKHTIN, M. Estética da criação verbal. São Paulo: Martins Fontes, 2003. p.261-306.

BECKER, Fernando. Educação e Construção do Conbecimento. Porto Alegre: Artmed, 2001.

BITTENCOURT, Circe Maria Fernandes. Livro didático e conbecimento histórico: uma história do saber escolar. Tese de Doutorado. São Paulo, 1993. Disponível em: https://www.teses.usp.br/teses/ disponiveis/8/8138/tde-28062019-175122/publico/1993_CirceMariaFernandesBiiencourt.pdf. Acesso em 12 abril 2021.

BRASIL. Decreto-Lei ñ 93, De 21 De Dezembro De 1937. Disponível em: https://www2.camara.leg.br/ legin/fed/declei/1930-1939/decreto-lei-93-21-dezembro-1937-350842-norma-pe.html Acesso em 12 abril 2021.

BRASIL. Lei-Decreto n 1006, de 30 de dezembro de 1938. Disponível em: https://www2.camara.leg.br/ legin/fed/declei/1930-1939/decreto-lei-1006-30-dezembro-1938-350741-publicacaooriginal-1-pe.html. Acesso em 12 abril 2021.

BRASIL. Decreto n 59.355, de 4 De Outubro De 1966. Disponível em: https:/ /www2.camara.leg.br/ legin/fed/decret/1960-1969/decreto-59355-4-outubro-1966-400010-publicacaooriginal-1-pe.html. Acesso em 12 abril 2021.

BRASIL. Decreto no 91.542, de 19 de Agosto de 1985. Disponível em: https://www2.camara.leg.br/ legin/fed/decret/1980-1987/decreto-91542-19-agosto-1985-441959-publicacaooriginal-1-pe.html. Acesso em 12 abril 2021.

BRASIL. Ministério da Educação. Base Nacional Comum Curricular. Brasília: MEC/SEMT, 2017 Disponível em: http://basenacionalcomum.mec.gov.br/images/BNCC_20dez_site.pdf. Acesso em 02 jan 2021.

BUNZEN, Clécio. O tratamento do conceito de gramática nos livros didáticos. Ao pé da letra, Revista dos alunos de Graduação em Letras, v. 2, 2000. Disponível em https://periodicos.ufpe.br/revistas/pedaletra/ article/download/230976/24969. Acesso em 12 abril 2021. 
BUNZEN, Clécio. A fabricação da disciplina escolar Português. Revista Diálogo Educacional, 2011 Disponível em: https://periodicos.pucpr.br/index.php/dialogoeducacional/article/view/4513. Acesso em 12 abril 2021.

DIONÍSIO, Ângela Paiva. Livros didáticos de Português formam professores? Brasília DF: Congresso Brasileiro de Qualidade na Educação: formação de professores, out., v. 1, n. 6. MEC/SEF, 2001 Disponível em: http://portal.mec.gov.br/seb/arquivos/pdf/vol1b.pdf. Acesso em 12 abril 2021.

FERREIRA, Rita Cássia Cunha. A Comissão Nacional do Livro Didático durante o Estado Novo (1937-1945). Dissertação de Mestrado. UNESP/ Assis, 2008. 139 f. Disponível em https://repositorio. unesp.br/bitstream/handle/11449/93413/ferreira_rcc_me_assis.pdf?sequence $=1$ \&isAllowed $=\mathrm{y}$ Acesso 17 jun. 2021

FILGUEIRAS, Juliana Miranda. As políticas para o livro didático durante a ditadura militar: a Colted e a Fenname. História da Educação, v. 19, n. 45, jan/abr. 2015. Disponível em: https://www.scielo.br/ scielo.php?script=sci_arttext\&pid=S2236-34592015000100085\&lng=pt\&tlng=pt. Acesso em: 25 fev. de 2021.

GERALDI, João Wanderley. Portos de passagem. 2ed. São Paulo: Martins Fontes, 1997.

GIL, Antônio Carlos. Como elaborar projetos de pesquisa. São Paulo: Atlas, 2002.

KOCH, Ingedore Grunfeld Villaça. Desvendando os segredos do texto. São Paulo: Cortez, 2006.

KOCH, Ingedore Grunfeld Villaça. ELIAS, Vanda Maria. Ler e escrever. estratégias de produção textual. São Paulo: Contexto, 2013.

LINS, Osman. Do ideal e da glória: problemas inculturais brasileiros. São Paulo: Summus, 1977.

MARCUSCHI, Luiz Antônio. Compreensão de texto: algumas reflexões. In: DIONÍSIO, Ângela Paiva.; BEZERRA, Maria Auxiliadora. O livro didático de português: múltiplos olhares. Rio de Janeiro: Lucerna, 2005.

OLIVEIRA, Tânia Amaral; ARAÚJO, Lucy Aparecida Melo. Tecendo Linguagens: Língua Portuguesa: 8o ano. 5. ed. Barueri: Ibep, 2018.

PATRIOTA, Luciene Maria. Aspectos Estruturais Dos Livros Didáticos De Português: Um Olhar Ao Longo Do Tempo. Revista Leia Escola, v. 15, n. 1, 2015.

ROLIM, Horácio.; MAGALHÃES, Jorge. Português Curso Ginasial 3. Editora do Brasil, 1969.

SAVIANI, Demerval. Pedagogia histórico-crítica: primeiras aproximações. Campinas: Autores Associados, 2013.

SILVA OTA, Ivete Aparecida da. O livro didático de língua portuguesa no Brasil. Educar em Revista, n. $35,2009$.

SOARES, Magda. Português na escola: história de uma disciplina curricular. In. BAGNO, M. (org) Linguística da norma. São Paulo: Loyola, p. 155-177, 2002. 